\title{
The cost and benefit of anti-TNF therapy from a population perspective-for what it's worth
}

\author{
Joseph D. Frasca ${ }^{1}$, Adam S. Cheifetz ${ }^{2}$ \\ ${ }^{1}$ Univeristy of Vermont Medical Center, Burlington, VT, USA; ${ }^{2}$ Center for Inflammatory Bowel Disease, Beth Israel Deaconess Medical Center, \\ Boston, MA, USA \\ Correspondence to: Joseph D. Frasca, MD. Division of Gastroenterology and Hepatology University of Vermont Medical Center, 111 Colchester \\ Avenue, Smith 251, Burlington, VT 05401, USA. Email: Joseph.Frasca@uvmhealth.org. \\ Provenance: This is an invited article commissioned by the Section Editor Dr. Wei Liu, PhD (Department of Gastroenterology of Yichang Central \\ People's Hospital, Institute of Digestive Disease, China Three Gorges University, Yichang, China). \\ Comment on: Murthy SK, Begum J, Benchimol EI, et al. Introduction of anti-TNF therapy has not yielded expected declines in hospitalisation and \\ intestinal resection rates in inflammatory bowel diseases: a population-based interrupted time series study. Gut 2019. [Epub ahead of print].
}

Submitted Dec 03, 2018. Accepted for publication Dec 13, 2019.

doi: $10.21037 / \mathrm{atm} .2019 .12 .86$

View this article at: http://dx.doi.org/10.21037/atm.2019.12.86

Anti-tumor necrosis factor therapy (ant-TNF) has dramatically changed the treatment of both Crohn's disease (CD) and ulcerative colitis (UC). The efficacy of this class of therapy has been established since the late 1990s when infliximab was shown to be effective in the treatment of moderate to severe CD and later fistulizing CD and UC (1-4). Since this time, additional anti-TNF agents have demonstrated efficacy in moderate to severe inflammatory bowel disease (IBD), including adalimumab $(5,6)$ for both $\mathrm{CD}$ and UC and golimumab $(7,8)$ for UC. In addition, several studies have further demonstrated the longterm efficacy of these agents based on both randomized controlled trials (RCT) and real-world data (9-11). While anti-TNF therapy has offered an effective treatment option for both CD and UC, the associated high costs of using these agents is often considered a drawback from a population standpoint. Several studies have demonstrated that the increased cost associated with using anti-TNF therapy has now surpassed hospitalization and surgery as the highest healthcare expenditure in patients with IBD (12-14).

With the costs associated with using anti-TNF, it is intuitively important to ensure the resultant benefit from a standpoint of long-term treatment outcomes, such as hospitalizations and surgery. However, the data on this is conflicting. A follow-up study of A Crohn's Disease Clinical Trial Evaluating Infliximab in a New Long-Term
Treatment Regimen in Patients with Fistulizing Crohn's Disease (ACCENT) II showed significant reduction in hospitalizations $(11 \%$ vs. $31 \%, \mathrm{P}<0.05)$ and surgeries and procedures $(65$ vs. $126, \mathrm{P}<0.05)$ with patients who received infliximab $5 \mathrm{mg} / \mathrm{kg}$ every 8 weeks (15). Similarly, a followup study from the Active Ulcerative Colitis Trial (ACT)1 and ACT-2 showed significantly reduced colectomy rates after 54 weeks of treatment with infliximab $(10 \%$ vs. $17 \%, \mathrm{P}=0.02$ ) (16). Lastly, a follow-up of The Crohn's Trial of the Fully Human Antibody Adalimumab for Remission Maintenance (CHARM) showed reduced risks of hospitalization (HR 0.42, $\mathrm{P}<0.05)$ and $\mathrm{CD}$-related surgeries ( $0.6 \%$ vs. $3.8 \% ; \mathrm{P}<0.05$ ) (17). While these follow-up studies from RCTs showed a clear benefit of anti-TNF in reducing hospitalizations and surgery, population-based studies have not shown such promising results. One study using data from a register-based observational cohort in Sweden showed that there was no difference in bowel resection rates in patients who continued anti-TNF therapy beyond 12 months compared to patients who discontinued prior to 12 months (18). Another study from the US evaluated claims data in UC patients and showed that over $50 \%$ of patients initiating infliximab, adalimumab, and golimumab remained on steroids after 12 months of treatment (19).

Most recently, a well-done population-based study from Ontario, Canada by Murthy et al. published in Gut showed that anti-TNF therapy has not led to expected declines 
in rates of hospitalization and intestinal resection (20). This study evaluated adult patients with CD and UC living in Ontario, Canada between 1995 and 2012 using an administrative claims database. This database is considered effective for capturing true population-level data and trends since Ontario uses a single payer system with 100\% coverage for medically necessary services and occasionally subsidized coverage for select expensive drugs, such as biologic therapies. The study utilized an interrupted time series design where trends 6 years prior to the introduction of infliximab were compared to trends after the introduction of infliximab into the Canadian marketplace. Overall, the results showed that there was no significant change in expected hospitalization rates for CD (OR 0.1.06, 95\% CI: $0.811-1.39$ ) or UC (OR 1.22, 95\% CI: $1.07-1.39$ ). There was also no significant change in expected intestinal resection rates for patients with CD (OR 1.10, 95\% CI: $0.810-1.50)$ or in colectomy rates for patients with $\mathrm{UC}$ (OR 0.933, 95\% CI: $0.540-1.61)$. However, there was a decline in hospitalizations for UC in the small subgroup of patients who received publicly funded infliximab (OR 0.515, 95\% CI: 0.342-0.777).

While these results may seem surprising, it is important to note a few reasons why the results of this study should be interpreted with caution. First, even though the design of this interrupted time study is unlikely to be impacted by other competing factors, there is a lack of detailed clinical data to determine the effect of confounding patient variables. Disease severity, one such potential confounding factor in similar population-based studies, and the impact of disease severity on the results of this study cannot be assessed. This is especially true for the CD population where there was strong penetration of infliximab into the marketplace as evidenced by a threefold increase in expected drug costs after marketplace introduction (OR 2.98, 95\% CI: 2.29-3.86). Therefore, it is plausible that patients with more severe CD were being treated with infliximab, and this may have impacted treatment outcomes. Also, because publicly-funded infliximab patients were required to first demonstrate failure to conventional therapy, it is also reasonable to believe that some patients were being treated later in the disease course when the efficacy of anti-TNF may be limited. This is supported by the pivotal studies on anti-TNF therapy that demonstrated higher clinical remission rates in the studies where participants had a shorter disease duration (2,6,21-23). On the other hand, the cost trends for patients with UC were different, highlighting another limitation in interpreting this study. Unlike for
$\mathrm{CD}$, the marketplace penetration of infliximab for patients with UC appeared to be low based on the lack of significant change in drug cost after introduction of the drug (OR 1.06, $95 \%$ CI: $0.955-1.18)$. Therefore, it is plausible that low drug usage in patients with UC was a primary factor that accounted for the lack of overall improvement in trends for hospitalization and surgery. Similarly, there may have not been enough time in the marketplace for the beneficial effects of UC to be demonstrated at a population-based level.

While the limitations in the study by Murthy et al. and its design are well-acknowledged by the authors, there are several other potential explanations for why there was a lack of decline in hospitalizations and surgery that pertain to treatment paradigms on when and how infliximab was used. The timing of infliximab initiation in relation to a patient's disease course is important. It has been demonstrated that there is likely a "therapeutic window" for biologic therapy when initiation of therapy early in the disease course may prevent disease-related complications, such as stricture, fistula/abscess, and surgery (24). Also, a "top-down" approach to therapy demonstrated benefit in a landmark RCT by D'Haens et al. (21), favoring early biologic usage prior to treatment with conventional therapy. Similarly, a post-hoc analysis of the CHARM trial showed that there was likely a benefit to treatment early in the disease course (25). In this analysis, patients with IBD were required to fail conventional therapy prior to anti-TNF use. This factor may account for the lack of improvement in hospitalizations and surgeries. This notion is further supported by a recent population-based pediatric study, also from Canada, that showed that a parallel relationship between early usage of anti-TNF therapy and reduction in corticosteroid dose (26).

Furthermore, another factor that may account for why there was a perceived lack of benefit with infliximab usage at a population level pertains to how infliximab was used. Even though infliximab has been available for 20 years, the treatment paradigms for infliximab and other biologic therapies have evolved, and in fact, are still evolving. The timing of anti-TNF discontinuation (i.e., definition of treatment "failure" and lack of optimization), the role of concomitant immunomodulator use, goals of therapy, and the role of therapeutic drug monitoring (TDM) have changed greatly since infliximab was first introduced into the marketplace. Additional real-world population-based studies have shown that there is a high rate of discontinuation and non-persistence of biologic therapies among patients with CD and UC $(27,28)$. Based on this observation and the lack 
of a standardized definition of treatment failure, early antiTNF discontinuation (i.e., lack of dose optimization) may be another factor that helps account for the absence of a population-level benefit for anti-TNF therapy. Also, the benefit of combination therapy with an immunomodulator has been demonstrated in both CD and UC by The Study of Biologic and Immunomodulator Naïve Patients in Crohn's Disease (SONIC) ${ }^{22}$ and UC-SUCCESS Trials (29), respectively. In addition, two population-based studies have shown that early combination therapy with an immunomodulator may lead to biologic drug persistence and increased effectiveness $(28,30)$. However, in the present study by Murthy et al., the penetration of concomitant immunomodulator use and its impact on disease outcomes at the population level are unknown. Therefore, underuse of combination therapy may have contributed to the observed lack of benefit from anti-TNF therapy. Furthermore, goals of therapy are changing with increasing evidence to support the objective outcomes including mucosal healing. Several studies have demonstrated the benefit of mucosal healing on long-term outcomes (31-34). Most recently, Yzet et al. showed that complete mucosal healing with a Crohn's disease endoscopic index score (CDEIS) of 0 led to lower rates of treatment failure ( $25 \%$ vs. $48 \%, \mathrm{P}=0.045)$, intestinal resection $(0 \%$ vs. $11 \%$, $\mathrm{P}=0.031$ ), and CD-related hospitalizations (3.5\% vs. $18 \%$, $\mathrm{P}=0.013$ ) over a median follow-up period of 4.8 years (35). From a population perspective, it is difficult to know whether the mucosal healing as a treatment target had been widely utilized and accepted, but based on the time period of this study, it is unlikely. This provides another plausible explanation for why there has been no observed benefit for anti-TNF therapy from a population-based perspective. Lastly, and perhaps most importantly, the beneficial role of proactive TDM is becoming increasingly demonstrated and recognized (36). A recent well-designed RCT by Assa et al. showed improved corticosteroid-free clinical remission from week 8 to week 72 ( $82 \%$ vs. $48 \%, \mathrm{P}=0.002$ ) in pediatric patients with $\mathrm{CD}$ who underwent proactive TDM compared with reactive TDM (37). Also, a previous retrospective study of 264 patients with $C D(n=167)$ and UC $(n=97)$ from multiple centers showed less treatment failure (HR 0.16, 95\% CI 0.09-0.27), fewer IBD-related surgeries (HR 0.30, 95\% CI: 0.07-0.33), less antibodies to infliximab (HR $0.25,95 \%$ CI: 0.07-0.84), and fewer serious infusion reactions (HR 0.17, 95\% CI: 0.04-0.78) in patients treated with proactive $v s$. reactive TDM of infliximab (38). With this said, the use of proactive TDM at a population level is unknown, and it is plausible that increased uptake of this beneficial practice would finally allow us to see a population-based benefit of anti-TNF.

\section{Acknowledgments}

None.

\section{Footnote}

Conflicts of Interest: AS Cheifetz: Consulting: Janssen, Abbvie, Takeda, Pfizer, Samsung, Arena, Bacainn, EMD Serono, Arsanis, Grifols, Prometheus; Research support: Inform Diagnostics. The other author has no conflicts of interest to declare.

Ethical Statement: The authors are accountable for all aspects of the work in ensuring that questions related to the accuracy or integrity of any part of the work are appropriately investigated and resolved.

\section{References}

1. Targan SR, Hanauer SB, van Deventer SJ, et al. A shortterm study of chimeric monoclonal antibody cA2 to tumor necrosis factor alpha for Crohn's disease. Crohn's disease cA2 Study Group. N Engl J Med 1997;337:1029-35.

2. Hanauer SB, Feagan BG, Lichtenstein GR, et al. Maintenance infliximab for Crohn's disease: the ACCENT I randomised trial. Lancet 2002;359:1541-9.

3. Rutgeerts P, Sandborn WJ, Feagan BG, et al. Infliximab as induction and maintenance therapy for ulcerative colitis. N Engl J Med 2005;353:2462-76.

4. Sands BE, Anderson FH, Bernstein CN, et al. Infliximab maintenance therapy for fistulizing Crohn's disease. $\mathrm{N}$ Engl J Med 2004;350:876-85.

5. Sandborn WJ, van Assche G, Reinisch W, et al. Adalimumab induces and maintains clinical remission in patients with moderate-to-severe ulcerative colitis. Gastroenterology 2012;142:257-65.e1-3.

6. Colombel JF, Sandborn WJ, Rutgeerts P, et al. Adalimumab for maintenance of clinical response and remission in patients with Crohn's disease: the CHARM trial. Gastroenterology 2007;132:52-65.e1-3.

7. Sandborn WJ, Feagan BG, Marano C, et al. Subcutaneous golimumab induces clinical response in patients with moderate-to-severe ulcerative colitis. Gastroenterology 2014;146:85-95; quiz e14-5. 
8. Sandborn WJ, Feagan BG, Marano C, et al. Subcutaneous golimumab maintains clinical response in patients with moderate-to-severe ulcerative colitis. Gastroenterology 2014;146:96-109.e1.

9. Panaccione R, Colombel JF, Sandborn WJ, et al. Adalimumab maintains remission of Crohn's disease after up to 4 years of treatment: data from CHARM and ADHERE. Aliment Pharmacol Ther 2013;38:1236-47.

10. Colombel JF, Sandborn WJ, Ghosh S, et al. Four-year maintenance with adalimumab in patients with moderately to severely active ulcerative colitis: Data from ULTRA 1, 2, and 3. Am J Gastroenterol 2014;109:1771-80.

11. Bressler B, Williamson M, Sattin B, et al. Real World Effectiveness of Golimumab Therapy in Ulcerative Colitis Regardless of Prior TNF Exposure. J Can Assoc Gastroenterol 2018;1:129-34.

12. Targownik LE, Witt JC, Tennakoon A, et al. Mo1871 Direct Costs of Care Among Patients with Inflammatory Bowel Disease before and after Initiation of Anti-TNF Therapy. Gastroenterology 2018;154:S-833.

13. Kappelman MD, Rifas-Shiman SL, Porter CQ, et al. Direct health care costs of Crohn's disease and ulcerative colitis in US children and adults. Gastroenterology 2008;135:1907-13.

14. van der Valk ME, Mangen MJ, Leenders M, et al. Healthcare costs of inflammatory bowel disease have shifted from hospitalization and surgery towards anti-TNF therapy: Results from the COIN study. Gut 2014;63:72-9.

15. Lichtenstein GR, Yan S, Bala M, Sands BE. Infliximab maintenance treatment reduces hospitalizations, surgeries, and procedures in fistulizing Crohn's disease. Gastroenterology 2005;128:862-9.

16. Sandborn WJ, Rutgeerts P, Feagan BG, et al. Colectomy rate comparison after treatment of ulcerative colitis with placebo or infliximab. Gastroenterology 2009;137:1250-60.

17. Feagan BG, Panaccione R, Sandborn WJ, et al. Effects of adalimumab therapy on incidence of hospitalization and surgery in Crohn's disease: results from the CHARM study. Gastroenterology 2008;135:1493-9.

18. Eberhardson M, Söderling JK, Neovius M. Anti-TNF treatment in Crohn's disease and risk of bowel resection a population based cohort study. Aliment Pharmacol Ther 2017;46:589-98.

19. Long MD, Smith TW, Dibonaventura M, et al. Realworld Effectiveness of Advanced Therapies Among Patients With Moderate to Severe Ulcerative Colitis in the United States. Inflamm Bowel Dis 2019 [Epub ahead of print].

20. Murthy SK, Begum J, Benchimol EI, et al. Introduction of anti-TNF therapy has not yielded expected declines in hospitalization and intestinal resection rates in inflammatory bowel diseases: a population-based interrupted time series study. Gut 2019. [Epub ahead of print].

21. D'Haens G, Baert F, van Assche G, et al. Early combined immunosuppression or conventional management in patients with newly diagnosed Crohn's disease: an open randomised trial. Lancet 2008;371:660-7.

22. Colombel JF, Sandborn WJ, Reinisch MD, et al. Infliximab, Azathioprine, or Combination Therapy for Crohn's Disease. N Engl J Med 2010;362:1383-95.

23. Lémann M, Mary JY, Duclos B, et al. Infliximab plus azathioprine for steroid-dependent Crohn's disease patients: a randomized placebo-controlled trial. Gastroenterology 2006;130:1054-61.

24. Pariente B, Cosnes J, Danese S, et al. Development of the Crohn's disease digestive damage score, the Léman score. Inflamm Bowel Dis 2011;17:1415-22.

25. Schreiber S, Reinisch W, Colombel JF, et al. Subgroup analysis of the placebo-controlled CHARM trial: increased remission rates through 3 years for adalimumab-treated patients with early Crohn's disease. J Crohns Colitis 2013;7:213-21.

26. El-Matary W, Leung S, Tennakoon A, et al. Trends of Utilization of Tumor Necrosis Factor Antagonists in Children with Inflammatory Bowel Disease: A Canadian Population-Based Study. Inflamm Bowel Dis 2020;26:134-8.

27. Jung YS, Han M, Park S, et al. Biologic Use Patterns and Predictors for Non-persistence and Switching of Biologics in Patients with Inflammatory Bowel Disease: A Nationwide Population-Based Study. Dig Dis Sci 2019. [Epub ahead of print].

28. Chen C, Hartzema AG, Xiao H, et al. Real-world Pattern of Biologic Use in Patients with Inflammatory Bowel Disease: Treatment Persistence, Switching, and Importance of Concurrent Immunosuppressive Therapy. Inflamm Bowel Dis 2019;25:1417-27.

29. Panaccione R, Ghosh S, Middleton S, et al. Combination Therapy With Infliximab and Azathiprine is Superior to Monotherapy With Either Agent in Ulcerative Colitis. Gastroenterology 2014;146:392-400.e3.

30. Targownik LE, Benchimol EI, Bernstein CN, et al. Upfront Combination Therapy, Compared with Monotherapy, for Patients Not Previously Treated 
With a Biologic Agent Associates With Reduced Risk of inflammatory Bowel Disease-related Complications in a Population-based Cohort Study. Clin Gastroenterol Hepatol 2019;17:1788-98.e2.

31. Frøslie KF, Jahnsen J, Moum BA, et al. Mucosal healing in inflammatory bowel disease: results from a Norwegian population-based cohort. Gastroenterology 2007;133:412-22.

32. D'haens G, Van Deventer S, Van Hogezand R, et al. Endoscopic and histological healing with infliximab anti-tumor necrosis factor antibodies in Crohn's disease: A European multicenter trial. Gastroenterology 1999;116:1029-34.

33. Schnitzler F, Fidder H, Ferrante M, et al. Mucosal healing predicts long-term outcome of maintenance therapy with infliximab in Crohn's disease. Inflamm Bowel Dis 2009; 15:1295-301.

34. Casellas F, Barreiro de Acosta M, Iglesias M, et al. Mucosal healing restores normal health and quality of life in patients with inflammatory bowel disease. Eur J Gastroenterol Hepatol 2012;24:762-9.

Cite this article as: Frasca JD, Cheifetz AS. The cost and benefit of anti-TNF therapy from a population perspectivefor what it's worth. Ann Transl Med 2019;7(Suppl 8):S388. doi: 10.21037/atm.2019.12.86
35. Yzet C, Diouf M, Le Mouel JP, et al. Complete Endoscopic Healing Associated With Better Outcomes Than Partial Endoscopic Healing in Patients With Crohn's Disease. Clin Gastroenterol Hepatol 2019. [Epub ahead of print].

36. Papamichael K, Cheifetz AS. Is It Prime Time for Proactive Therapeutic Drug Monitoring of Anti-Tumor Necrosis Factor Therapy in Inflammatory Bowel Disease? Gastroenterology 2019;157:922-4.

37. Assa A, Matar M, Turner D, et al. Proactive Monitoring of Adalimumab Trough Concentration Associated With Increased Clinical Remission in Children with Crohn's Disease Compared With Reactive Monitoring. Gastroenterology 2019;157:985-96.e2.

38. Papamichael K, Chachu KA, Cheifetz AS, et al. Improved Long-term Outcomes of Patients With Inflammatory Bowel Disease Receiving Proactive Compared With Reactive Monitoring of Serum Concentrations of Infliximab. Clin Gastroenterol Hepatol 2017;15:1580-8.e3. 